\title{
ERA UMA CASA ...!? DISCURSO, DINÂMICA FAMILIAR E CONTINGÊNCIAS DA RUA ${ }^{1}$
}

\author{
Paula Cristina Monteiro de Barros \\ Albenise de Oliveira Lima \\ Nanette Zmeri Frej" \\ Maria de Fátima Vilar de Melo ${ }^{\infty}$
}

\begin{abstract}
RESUMO. Crianças e adolescentes em situação de rua refletem um sintoma social marcado essencialmente por violência, transgressões, abandono e a precocidade que a vida na rua impõe. Uma realidade perpassada por aspectos sociais, políticos, culturais, históricos, econômicos, que configuram uma complexa trama social. Na experiência em uma instituição (Olinda - Brasil), deparamonos com sujeitos com histórias singulares, que adotaram a mesma saída - a rua — para o conflito vivido. Partindo de um recorte dessa realidade, propomos uma leitura de aspectos da dinâmica familiar que fragilizam o sujeito, como as palavras que lhe são endereçadas, as quais o marcam com atributos que culminam com a identidade "menino de rua". Que lugar é atribuído ao sujeito que faz um rompimento com a casa e a família? Propomos também pensar estratégias de intervenção junto às famílias no sentido de restituir ou construir um lugar de pertencimento para essas crianças e para esses pais no âmbito familiar..
\end{abstract}

Palavras-chave: Crianças e adolescentes, situação de risco social, endereçamento.

\section{IT WAS A HOME...!? SPEECH, FAMILY DYNAMICS AND CONTINGENCIES OF THE STREET}

\begin{abstract}
Children and adolescents who live on the street reflects a social symptom, marked, essentially, by violence, transgression, desertion and the precociousness that the life on the street imposes. A reality configured by social, political, cultural, historical, economic aspects, which compose a social complex. From the experience at an institution (Olinda-Brazil), we find subject with singular histories, who adopted the same solution — the street — to the experienced conflict. From a cut in this reality, we propose a reading of aspects from the family dynamics, which weaken the subject, like the addressed words to him, which mark with attributes that result in the identity "Child of the Streets". What place is given to the subject that makes a break with the home and the family? We also propose to think strategies for intervention with the families to restore or build a place of belonging for these children and these parents in family.
\end{abstract}

Key words: Children and adolescents, social risk, addressing.

\section{¿ERA UNA CASA ...!? DISCURSO, DINÁMICA FAMILIAR Y CONTINGENCIAS DE LA CALLE}

RESUMEN. Niños y adolescentes en situación de calle reflejan un síntoma social marcado esencialmente por la violencia, por las transgresiones, por el abandono y por el comportamiento precoz que la vida por la calle se impone. Una realidad configurada por aspectos sociales, políticos, culturales, históricos, económicos, que se enlazan en una compleja trama social. En la experiencia en una institución (Olinda - Brasil), nos deparamos con sujetos con historias singulares, pero que adoptaron la misma salida - la calle - para el conflicto que han vivido. A partir de un recorte de esa realidad, hemos propuesto una lectura de aspectos de la dinámica familiar que fragilizan el sujeto, como las palabras que son dirigidas a ellos, os marcan con la identidad "niños de calle". ¿Qué sitio es atribuido al sujeto que hace un rompimiento con la casa y con la familia? A partir

Apoio CAPES/PROSUP.

Psicóloga clínica, Mestre em Psicologia Clínica pela Universidade Católica de Pernambuco -UNICAP.

\# Professora Pesquisadora do curso de Psicologia e do Programa de Pós-Graduação em Psicologia Clínica da Universidade Católica de Pernambuco - UNICAP; Doutora em Saúde e Família pela Universidade de Deusto (1998).

Il Psicanalista, Professora Pesquisadora do curso de Psicologia e do Programa de Pós-Graduação em Psicologia Clínica da Universidade Católica de Pernambuco - UNICAP; Doutora em Psicologia pela Université Paris XIII; Pós-Doutora em Psicologia pela Université Paris VII e Membro da Association Lacanienne Internationale.

x Professora Pesquisadora do curso de Psicologia e do Programa de Pós-Graduação em Ciências da Linguagem da Universidade Católica de Pernambuco - UNICAP. Doutora em Psicologia pela Université Paris V. 
de esa lectura, es nuestro propósito, también, pensar estrategias de intervención junto a la familia en el sentido de restituir o construir un sitio de pertenencia para esos niños, pero también para los padres en el ámbito familiar.

Palabras-clave: Niños y adolescentes, situación de riesgo social, direccionamiento.

Era uma casa / Muito engraçada / Não tinha teto / Não tinha nada / Ninguém podia entrar nela, não / Porque na casa não tinha chão / Ninguém podia dormir na rede / Porque na casa não tinha parede / Ninguém podia fazer pipi / Porque penico não tinha ali / Mas era feita com muito esmero / Na rua dos Bobos / Número zero. (Vinícius de Moraes)

O fascínio de um grupo de adolescentes, ao ouvir essa música, e pedir para repeti-la chamou a atenção, especialmente pelo que mobilizou, num jovem, há nove anos na rua, sem contato com a família. Uma música que norteou por meses os atendimentos a uma criança que cantava sem cessar e convocava a psicóloga a acompanhá-lo, ficando, por vezes, somente a ouvi-la, como que a ouvir uma cantiga de ninar.

Uma música que remete às lembranças de uma casa, recordando um passado às vezes distante, mas que também parece descrever a rua: um lugar sem teto, sem paredes, sem número, um lugar sem delimitação, um lugar que é tomado como moradia. Qual a "graça" e qual a configuração dessa "casa muito engraçada" que, na família ou na rua, é inscrita na e pela violência?

A trajetória de Renata ${ }^{2}, 13$ anos, é acompanhada por uma atribuição de culpa violenta, pois sua família a considera responsável: pela morte de seu pai, devido ao fato dela, ainda bebê, ter chorado no berço quando vieram assassiná-lo; por ter induzido seus irmãos, mesmo os mais velhos, à vivência de rua; e, ainda, pela morte da mãe, cuja saúde teria se agravado em decorrência das preocupações com a filha. João, 16 anos, teve seu pai, João, assassinado quando tinha 28 dias de vida. Começou a ir para a rua aos nove anos, quando conheceu a família paterna. Recentemente, João foi assassinado por causas desconhecidas. A mãe de Pedro, 15 anos, nunca lhe contou a história de seu pai - que foi assassinado por envolvimento com tráfico - pois receia que ele siga o mesmo caminho. "Não sei por que, mas ele sempre vai cheirar cola na Prainha, no mesmo lugar que o pai dele foi morto".

Bruno, 12, há cinco anos alterna entre a casa e a rua, onde é violentado e explorado pelos mais velhos. Numa reunião de família, seu padrasto comenta: "O Governo agora deu pra querer fazer de bicho gente".

${ }^{2}$ Os nomes aqui citados são fictícios.
O pai de Ricardo, 17, um senhor de 72 anos, não pôde criá-lo, por ser ele filho de sua amante. Aos dois anos, Ricardo foi colocado numa roda de fogo, pois julgavam que tinha um demônio no corpo. "A senhora queria que sua mãe lhe chamasse de filho do demônio e quisesse que você morresse?". Leandro, 18, passou quatro anos na rua, sem contato com a família. Deturpava sua história, tendo dado seu nome verdadeiro após seis meses de acompanhamento. $\mathrm{Na}$ volta para casa, o que se deu por determinação judicial, conheceu quatro novos irmãos. Numa visita domiciliar, a mãe diz que ele passou quatro anos longe de casa e ele responde: "4 anos, 11 meses e 5 dias".

Histórias que falam da especificidade da dinâmica de cada família em particular. Sujeitos com percursos singulares, mas que, entretanto, adotaram a mesma saída para o conflito vivenciado: viver na rua. Que elementos se repetem e permitem compreender a identidade "menino de rua", o deslocamento da casa à rua? A partir dessa leitura, propomos pensar intervenções junto a um público específico — crianças e adolescentes em situação de rua e suas famílias naquilo que é peculiar à vivência de rua.

Por que um rompimento com a casa, com a família, tomando a rua como espaço de moradia e que representação têm os significantes "casa" e "rua" depois de seu abandono e de sua "escolha", respectivamente?

É importante destacar que as crianças e os adolescentes em situação de rua transcendem o núcleo familiar, na medida em que se trata de uma problemática macrossocial, norteada por questões sociais, políticas, culturais, históricas e econômicas. De acordo com Rizzini (2003, p.34), somente nos últimos anos do século XX, as pesquisas passaram a apresentar novos focos de atenção, deslocando a ênfase do "problema da criança" para o que seria a verdadeira origem do problema, ou seja, “(...) os múltiplos fatores que contribuíram para 'produzir' ou 'fabricar' 'meninos/as de rua",.

Lucchini (2003, p.48) considera a questão uma categoria heterogênea. Para ele, a ‘criança de rua' é definida por uma dimensão física - tempo que a criança passa na rua - e uma dimensão social relações ou não-relações com os pais ou outros adultos responsáveis. Identifica, ainda, alguns fatores: 1.biológicos (idade, sexo); 2. diretamente ligados à família (composição, organização familiar e laços 
afetivos); 3. ligados à rua (representações da rua, grupos na rua); 4. ligados ao espaço urbano (lugares por onde a criança circula); e 5. macroscópicos (situação econômica, política e social do país).

Desse modo, considerar os fatores ligados à família não implica desconsiderar os demais, mas promover um recorte que possibilite a leitura de aspectos percebidos na dinâmica familiar, os quais, de certo modo, fragilizam o sujeito, e, juntamente com os outros fatores, acarretam a busca pela rua. "Na rua, eu me sinto mais protegido, mais aliviado"; "Você pensa que eu gosto de ficar na rua? Eu não tenho pra onde ir"; "Minha casa é a rua". De que casa se trata quando se faz essa equivalência entre termos que se sustentam exatamente pela contraditoriedade de sentido?

\section{“ERA UMA CASA MUITO ENGRAÇADA...”: UMA DISTINÇÃO NECESSÁRIA}

Da Matta (1991, p.19) refere-se à "casa" e à "rua" como conceitos interdependentes que compõem “(...) um par estrutural que é constituído e constituinte na própria dinâmica de sua relação". Trata-se de categorias sociológicas fundamentais, que permitem compreender a forma como uma sociedade pensa sobre si mesma e institui como seu código de idéias e valores. Esferas de significação social definidas por éticas particulares, delineando a realidade por meio de perspectivas próprias.

$\mathrm{Na}$ casa, as questões são tratadas sob um prisma familiar, privado, íntimo, que enfatiza a pessoa, os processos e as situações, num contexto em que há uma intensidade emocional e que engloba o sujeito, confundindo-se com o espaço social nela inscrita. Por outro lado, na rua — um vazio sem borda (Ferreira, 2001) — tem-se acesso ao público, ao estranho, ao impessoal. A leitura do ambiente "rua" perpassa por discursos rígidos e instauradores de novos processos sociais que permitem a exclusão, a cassação, o banimento, a condenação. "[...] aqui passamos sempre por indivíduos anônimos e desgarrados, somos quase sempre maltratados pelas chamadas 'autoridades' e não temos nem paz, nem voz”. (DaMatta, 1991, p.22)

Arendt (1972, citado por Ferreira, 2001, p.25) considera a casa e a vida familiar que nela se estabelece como elementos fundamentais ao desenvolvimento da criança, na medida em que o retorno cotidiano de seus pais propicia-lhe um sentimento de constância e estabilidade. Para Bachelard (2000, citado por Ferreira, 2001, p.31) a casa é a "topografia do nosso ser íntimo", pois, a partir dela, o sujeito aprende a morar em si mesmo. "Sem ela, o homem seria um ser disperso. Ela mantém o homem através das tempestades do céu e das tempestades da vida. É corpo e é alma. É o primeiro mundo do ser humano". (p. 32)

A casa, então - enquanto continente que delimita as fronteiras entre o interno e o externo, o privado e o público, o eu e o não-eu - confere unidade ao ser, remetendo à idéia de relacionamento, de pertencimento, de acolhimento.

Retomamos a fala da adolescente "Minha casa é a rua", problematizando-a e pensando nas implicações subjetivas que esse deslocamento pode produzir. DaMatta (1991, p.58) destaca a inviabilidade de se misturar o espaço da rua com o da casa sem que haja qualquer forma de conflito. Expressões como "já para a rua", "vá para o olho da rua" exprimem a dramática ligação entre esses dois significantes e denotam “(...) o rompimento drástico com um grupo social e o conseqüente isolamento do indivíduo, agora obrigado a situar-se diante do mundo 'do olho da rua', isto é, de um ponto de vista impessoalizado e para nós 'desumano",.

Ferreira (2001, p.23) fala do fenômeno "estar no olho da rua", o qual “(...) denuncia a expulsão em seu estado mais bruto. $\mathrm{Na}$ rua, tudo se transforma e tudo se perde. A identidade... o nome, o rosto, a voz, o desejo". Indagamos, então, o movimento em torno do qual se constrói a identidade "menino de rua", dada à impessoalidade e ao anonimato que tão comumente marcam a trajetória dessas crianças e desses adolescentes.

\footnotetext{
(...) os efeitos dessa trajetória marcam o corpo e a vida desses adolescentes e, indubitavelmente, deixam traços na sua constituição subjetiva. Não sabemos em que medida tal trajetória tem o consentimento do sujeito, mas sabemos que não é sem efeito na sua posição subjetiva. A ida para a rua, quase sempre provocada pela miséria material ou pelo fracasso da provisão libidinal, será sempre uma resposta do sujeito. (Ferreira, 2001, p.19)
}

De que resposta se trata se, quando falamos em saída de casa, estamos falando em rompimento com a família, com os lugares que norteiam a sua dinâmica, em momentos, em geral, precoces e críticos do desenvolvimento? Que elementos da dinâmica familiar podem respaldar a compreensão da trajetória dessas crianças e desses adolescentes da casa à rua, esperando encontrar nesta uma “(...) saída para poderem existir" (Campolina, 2001, p.13)? 


\section{“...NÃO TINHA TETO NÃO TINHA NADA..”}

As famílias acompanhadas, em geral, são famílias numerosas, marcadas muitas vezes pela violência, pela carência afetiva e financeira, por ameaças na comunidade, por perda de parentes, pelo uso de drogas, pelo trabalho infantil, situações que demarcam uma vulnerabilidade e um comprometimento psicoafetivo e social intensos.

O grupo familiar gira em torno da mãe, envelhecida pela miséria e pela violência às quais se encontra submetida, sendo, às vezes, acometida por uma apatia paralisante e por algum sofrimento psíquico grave. Em nossa experiência no Centro de Referência para Infância e Adolescente.(Olinda - PE), o pai biológico, geralmente, não está presente - é desconhecido, foi assassinado por envolvimento com drogas, faleceu por complicações pelo uso abusivo de álcool, está desempregado, constituiu outra família. Em algumas casas, faz-se comum a presença de um padrasto, com o qual a criança ou o adolescente dificilmente mantém um bom relacionamento, haja vista ser sua imagem remetida a episódios de agressão contra a mãe ou contra eles. Em pesquisa realizada pela referida instituição (2007), identificamos que dos oitenta e oito usuários acompanhados direta ou indiretamente no ano de 2006, 43\% das famílias eram chefiadas pelas mães, enquanto que em apenas $16 \%$ dos casos, o pai estava presente enquanto chefe de família. Além deste dado, em $57 \%$ das famílias, a mãe era tida como única responsável, em $12 \%$ o casal estava presente, ao passo que em apenas $6 \%$ das famílias o pai aparecia como responsável.

Chama atenção a forma como respondem quando lhes é perguntado com quem moram. 'Com minha mãe', respondem, como se as outras pessoas residentes não tivessem um lugar demarcado. 'Moram você, sua mãe e quem mais?'. Somente então os outros integrantes são nomeados.

$\mathrm{Na}$ fala das crianças e dos adolescentes, a casa representa privação; conviver com o padrasto, que é alcoolista; com a mãe, que é "doente dos nervos"; com os muitos irmãos; com a lembrança muito presente do pai que foi assassinado; com a proibição do uso de substâncias psicoativas; com a agressividade; com a obrigação de ter que retornar para casa com uma quantia preestabelecida de dinheiro.

No contato com 128 famílias em que algumas de suas crianças estavam nas ruas, Alves (Rizzini, 2003, p.24/25) constatou que essas crianças provinham, em sua maioria, de lares chefiados por mulheres e apresentavam dificuldades em relação ao pai, revelando um "aspecto complexo e doloroso de depreciação da figura paterna". Vogel e Mello (citado por Rizzini, 2003, p.26) destacam o fascínio da rua como elemento de curiosidade e aventura; e, reforçando a existência do lar violento, o fenômeno da casa vazia, ou seja, a ausência de adultos de referência para a criança, a falta de cuidados e de rituais na família. A questão da liberdade oferecida e encontrada nas ruas é também abordada, o que para Hecht, citado por Rizzini (1998, p.30) implica "um ethos de rua baseado em espontaneidade, insubordinação à autoridade, e uma solidariedade com outros jovens extremamente rejeitados".

Diante desses aspectos, questionamo-nos por que outras crianças e adolescentes - em condições aparentemente "parecidas" — não fazem uma "escolha" semelhante. Por que, inclusive, numa mesma família, apenas alguns filhos - a minoria passam a viver nas ruas, enquanto os demais ficam em casa? Por que, nas situações de trabalho infantil, a maioria retorna para casa, enquanto outros se distanciam cada vez mais do convívio familiar? “(...) as crianças que sofrem das mesmas carências não vão todas para a rua (...) existe uma 'seleção' entre as crianças que partem e as que ficam" (Lucchini, 2003, p.45).

Sobre as relações construídas numa família, Winnicott (1999, p.128) destaca:

\begin{abstract}
Não se trata simplesmente de haver um pai e uma mãe, e de que talvez outras crianças apareçam com o tempo, passando então a existir um lar com pais e filhos, enriquecido com tias, tios, primos. (...) Para as cinco crianças de uma família, há cinco famílias. (...) essas cinco famílias não são necessariamente semelhantes, e sem dúvida não são iguais.
\end{abstract}

Passamos, então, a nos indagar sobre o lugar subjetivo - afora todo o "determinismo" da miséria e da violência - que essas crianças e esses adolescentes ocupam no seio familiar.

\section{“... NINGUÉM PODIA ENTRAR NELA NÃO...”: 0 LUGAR DO SUJEITO NA DINÂMICA FAMILIAR}

Ferreira (2001, p.34) considera a busca pela rua como decorrência da falta de oferecimento pelo social de um lugar simbólico que confira reconhecimento ao ser. "Uma escassez da oferta de significantes que permita pensar no lugar que o sujeito ocupa na estrutura familiar".

Consideramos a família enquanto unidade primeira de identificação e de organização social. 
Grupo primário, constituído a partir de laços libidinais, conforme atesta Freud em Psicologia de Grupo e a Análise do Ego ([1921]-1996). Uma dinâmica perpassada por desejos, lugares psíquicos, identificações, ambivalências, posições hierárquicas, construções imaginárias, mitos, historicidade. Núcleo essencial de constituição do sujeito, que, ao se reconhecer no desejo do Outro, constitui-se enquanto sujeito igualmente do desejo e da alteridade. Um grupo inscrito essencialmente no desejo, que é presentificado pelo discurso parental, que nomeia, que atribui significações e lugares na dinâmica familiar.

$\mathrm{O}$ sujeito nasce imerso numa cadeia de significantes que o antecedem, à medida que, antes de nascer, já fazia parte da trama familiar, sendo-lhe, portanto, atribuído e designado um lugar a ser ocupado no desejo dos pais. Falar em desejo atribuído aos filhos remete a toda uma historicidade do desejo e do lugar outrora atribuído aos pais, enquanto filhos, em suas famílias de origem. Em seu estudo sobre o narcisismo, Freud ([1914]-1996, p.98) afirma tratar-se de uma “(...) revivescência e reprodução de seu próprio narcisismo, que de há muito abandonaram”. Mais adiante, acrescenta:

A criança terá mais divertimentos que seus pais; ela não ficará sujeita às necessidades que eles reconheceram como supremas na vida. A doença, a morte, a renúncia ao prazer, restrições à sua vontade própria não a atingirão (...) ela será mais uma vez realmente o centro e o âmago da criação 'Sua Majestade o Bebê', como outrora nós mesmos nos imaginávamos. (p.98)

Perguntamo-nos o que se passa nessas famílias, quando o que está posto é um real avassalador, que denuncia a fome, a miséria, a violência. Mães feridas narcisicamente, cujos ideais foram, há muito, destruídos pela tragicidade da vida, pela violência que repetem com seus filhos, os quais denunciam uma situação anterior que também não foi simbolizada, como se nenhuma diferenciação fosse possível. O narcisismo aparece, então, como “(...) ferida que não cicatriza jamais, embora nos empurre para procurar outras relações, outros projetos que resgatem a ilusão de preenchimento, de unidade, de criação perfeita". (Kahn, 2002, p.116)

Winnicott (1999, p.139) destaca a relevância para o desenvolvimento emocional do sujeito de uma estabilidade ambiental que propicie a continuidade da experiência pessoal e o desenvolvimento da capacidade de "acreditar em". Quando privações, incidentes, acidentes perturbam essa continuidade, configurando-se enquanto padrão dos cuidados dispensados à criança, ela constrói uma falta de confiança no ambiente.

Ao destacar a situação de desamparo em que se encontra o bebê, Freud observa que o indivíduo fica à mercê de suas forças pulsionais, num sentimento de abandono perante o outro, o qual é convocado a atender à demanda pulsional, simbolizando-a; podendo, no entanto, tornar-se o responsável pela excitação excessiva, configurando uma vivência catastrófica. $\mathrm{O}$ apaziguamento da excitação depende da disponibilidade materna em simbolizar as necessidades da criança e oferecer-lhe o continente corporal adequado, evitando assim, que as contínuas vivências de desamparo caracterizem o modo de subjetivação desses sujeitos.

Se o corpo não encontra possibilidades de descarga para o seu estado de tensão, se o outro não surge como possibilidade de apaziguamento, será necessário encontrar outras vias de alívio para o estado de desprazer. Para Cecarelli, citado por Kahn (1998, p.127), em alguns casos, "O recurso à violência pode ser a única saída para se manter o mínimo de "saúde psíquica". Seria a busca pela rua uma das saídas possíveis - encontradas pelas crianças e pelos adolescentes - que a tomam como possibilidade de moradia?

Em Romances Familiares ([1909]-1996), Freud considera que se espera do indivíduo, ao crescer, libertar-se da autoridade dos pais, podendo constituir um processo doloroso. Uma vez representando os pais, a autoridade única e a figura de maior referência para a criança pequena, o seu desejo mais premente é identificar-se com eles. Idealização essa que vai, gradativamente, sendo substituída por um sentimento de frustração, na medida em que, face ao fracasso dos pais, a criança passa a pôr em dúvida as outrora incontestáveis atribuições, no que concerne à magnitude e ao amor soberano destes.

O sentimento de estar sendo negligenciado constitui obviamente o cerne de tais pretextos, pois existe sem dúvida um grande número de ocasiões em que a criança é negligenciada, ou pelo menos sente que é negligenciada, ou que não está recebendo todo o amor dos pais, e principalmente em que lamenta ter de compartilhar esse amor com seus irmãos e irmãs (Freud, [1909]1996, p.219).

Freud refere-se, então, ao romance familiar do neurótico, uma construção da criança, na tentativa de libertar-se dos pais, substituindo-os por outros 
considerados de maior apreço. O desenvolvimento dessas fantasias e a possibilidade de retaliação por meio destas dependerá do material à disposição da criança, podendo surgir uma grande variação dos romances familiares.

Poderemos falar em romance familiar nessas crianças e nesses adolescentes que põem em ato a libertação dos pais, ao invés de vivê-la, como é o caso do neurótico, em nível de fantasia? Consideramos que, no caso de crianças e adolescentes em situação de rua, parece faltar-lhe recursos para elaborar simbolicamente as situações, já que as dimensões traumáticas não são vividas apenas na fantasia, mas, sobretudo, concretamente, no real do corpo. A negligência de fato existe. $\mathrm{A}$ incerteza quanto à paternidade é, às vezes, legitimada e os pais, em geral, fracassam constantemente, de modo que a libertação dá-se precocemente e a retaliação é dirigida no real, à sociedade, no ambiente da rua.

Apesar da tentativa de se estabelecer um espaço de moradia na rua, com a busca de novas referências, a construção de relações, a demarcação de territórios aparentemente de propriedade de quem dele usufrui, não há, reconhecidamente, uma casa na rua, no sentido discutido acima. "Você não pode entrar aqui, porque essa minha casa está muito suja" - comenta uma adolescente de 12 anos num atendimento, ao entrar numa cabana de pano, enquanto falava de suas experiências na rua. Os desenhos de casas, geralmente, apresentam um aspecto de transparência, sendo possível perceber-se seu interior, o que aponta para uma continuidade indiferenciada entre dentro e fora, assim como o é a constituição de uma "casa" na rua.

Não há um espaço público que os sustente; disputa-se um espaço no público, abdicando-se do privado, mas não se tem nem um nem outro. Crianças e adolescentes destituídos que, em geral, apesar da dificuldade do retorno à casa e, às vezes, de sua inviabilidade mesmo, demonstram o desejo de que suas famílias sejam acompanhadas, assim como a necessidade de ouvir acerca do lugar que é por essas famílias a eles designado.

É muito peculiar o modo como as famílias aparecem em seus discursos. Alguns se negam a deixar entrever qualquer dado de identificação, limitando-se à designação que marca uma identidade: "sou menino de rua", emergindo, assim, como sujeitos "sem história", presentificados e subjetivados a partir das vivências e contingências da vida na rua. A maioria dos jovens, num primeiro momento, deturpa suas histórias, cria personagens, idealiza figuras que, para eles, deveriam existir, fornece dados contraditórios, mas deixa sempre escapar algo que aponta para um fio condutor de intervenção. Outros, ainda, mantêm uma imagem muito viva da dinâmica familiar - narram, repetidamente, fatos do passado, como que numa tentativa de assegurar a preservação de lembranças e o pertencimento a uma família — e, embora na rua, sinalizam - mesmo que de forma muito tênue — um desejo de volta.

\section{“(...) MAS ERA FEITA COM MUITO ESMERO, NA RUA DOS BOBOS, NÚMERO ZERO”: UMA POSSIBILIDADE DE INTERVENÇÃO}

Que escuta fazer dessas famílias que, de uma forma ou de outra — idealizada ou não, com ressentimento, com saudade ou com desprezo estão inscritas na subjetividade dessas crianças e desses adolescentes? De que modo intervir no sentido de facilitar o caminho de volta para casa, para o convívio familiar? Até que ponto se faz possível essa intervenção, no sentido da volta, e em que momento, mesmo dando continuidade ao acompanhamento familiar, constatar a inviabilidade do retorno - uma inviabilidade por nós considerada, na maioria das vezes, momentânea?

Constatar um certo desinvestimento das famílias em relação a seus filhos nos faz considerar que eles, de certo modo, denunciam com seus corpos, suas atuações, a fragilidade de suas famílias, aquilo que para os pais, as mães especificamente, é tido como fracasso. E, nesse sentido, mantê-los longe, pensamos, é uma forma de lidar com essas frustrações.

Por outro lado, apesar das constantes falas de que "esse menino não presta", "espero todo dia a notícia na televisão que ele foi morto", a possibilidade da escuta é sempre muito bem acolhida, e logo o discurso desliza para: "às vezes, eu acho que vou enlouquecer", “ele tá se comportando direito?", "ele tá dormindo mesmo na rua?"

Uma escuta que se dá no sentido de acolher um sentimento que se faz bastante legítimo e que permite convocar as mães a situarem seus filhos na sua história, bem como a situá-las em suas histórias, ocasiões em que se torna evidente, muitas vezes, a violência e a falta de um lugar de reconhecimento que lhe foi também endereçada. Uma mãe, ao falar de si, comenta: "Se eu raspar a cabeça, você vai ver quanta cicatriz eu tenho das surras que levei de meu pai", ao que o jovem responde: "Deixa eu raspar a minha pra tu ver se eu não tenho bem mais que você!"

Um retorno que, se por um lado, faz reviver situações que se preferiria esquecer, igualmente 
ameaça, na medida em que representa o confronto, conforme aponta Melo (1999), com a possibilidade de uma nova ruptura.

De acordo com Winnicott (2005, p.50), ao falar do retorno das crianças que foram evacuadas de suas casas em tempos de guerra,

(...) quando as crianças voltarem para casa, não irão necessariamente encaixar-se nos mesmos buracos que provocaram ao sair de casa, pela simples razão de que o buraco desapareceu. Mãe e filho tornaram-se capazes de se arranjar um sem o outro, e quando se reencontrarem terão de partir da estaca zero para voltarem a conhecer um ao outro.

A esse respeito, uma mãe relata: "Ele saiu daqui uma criança, voltou um homem (quatro anos depois). Eu não sei se ele roubou, se ele matou, não sei o que ele é capaz de fazer com os meus filhos". O adolescente, por sua vez, atribuía sempre um saber à psicóloga, durante as visitas. "Pergunte a ela, ela sabe". Criar um espaço em que mãe e filho pudessem contar um ao outro o que se passou, durante esses quatro anos, permitiu situá-los um em relação ao outro, ambos em relação à família. Uma intervenção, portanto, que percebemos como uma possibilidade de nomeação, de re-construção ou construção de um lugar de pertencimento, para as crianças e para os pais.

Uma possibilidade de se nomear e de se atribuir sentido a essa "casa" sem teto, sem nada, sem porta, sem chão, sem pinico, sem parede, mas uma casa que, ainda na rua dos Bobos, número zero, pode ser feita com muito esmero.

\section{REFERÊNCIAS}

Campolina, A. D. Prefácio. Em Ferreira, T. Os meninos e a rua. Uma interpelação à psicanálise. Belo Horizonte: Autêntica, 2001, p.13.

Centro de Referência para Infância e Adolescência (2007). Pesquisa sobre o perfil dos usuários atendidos em 2006. Olinda/PE: Barros, P.C.M; Chaves, M.N.C.; Novaes, M.F.; Ramos, V.F.; Sobral, M.L

DaMatta, R. A casa \& a rua. Rio de Janeiro: Editora Guanabara Koogan S.A., 1991. $4^{\circ}$ edição.

Ferreira, T. Os meninos e a rua. Uma interpelação à psicanálise. Belo Horizonte: Autêntica, 2001.

Freud, S. Romances Familiares. [1909] Em Obras completas. Rio de Janeiro: Imago, 1996, Vol.IX.

Freud, S. Sobre o Narcisismo: uma Introdução. [1914]. Em Obras Completas Rio de Janeiro: Imago, 1996, Vol. XIV.

Freud, S. Psicologia de Grupo e a Análise do Ego [1921]. Em Obras Completas. Rio de Janeiro: Imago, 1996, Vol.XVIII.

Kahn, I.S. Violências. São Paulo: Escuta/Fapesp, 2002.

Lucchini, R. A Criança em situação de rua: uma realidade complexa. Em Rizzini, I. (coord.). Vida nas ruas. Crianças e adolescentes nas ruas:trajetórias inevitáveis? Rio de Janeiro: PUC-Rio, 2003.

Melo, V. M. Da família à rua à família... passagens possíveis. Em Pulsional, Revista de Psicanálise. Ano XII. Número 12. Dezembro 1999, p. 4761.

Rizzini, I. (coord.). Vida nas ruas. Crianças e adolescentes nas ruas: trajetórias inevitáveis? Rio de Janeiro: PUC-Rio, 2003.

Winnicott, D. W. Tudo começa em casa. São Paulo: Martins Fontes, 1999.

Winnicott, D. W. Privação e delinquiência. São Paulo: Martins Fontes, 2005.

Recebido em 09/04/08 Aceito em 19/08/08 $\begin{array}{ll}\text { Endereço para correspondência : } & \text { Paula Cristina Monteiro de Barros. Rua Dom Sebastião Leme, 171/2201, Graças, CEP 52011- } \\ & \text { 160, Recife-PE, Brasil. E-mail: paulacmbarros@ @ol.com.br }\end{array}$ 